\title{
Phytochemical screening and determination of total phenolic and total flavonoid contents of pear peel extracts
}

\author{
Vinda Maharani Patricia ${ }^{[1]^{*}}$, Fauzia Ningrum Saputri ${ }^{[1]}$ \\ ${ }^{1}$ Department of Pharmacy, Faculty of Pharmacy, Universitas Muhammadiyah Bandung, Bandung, West Java, \\ Indonesia \\ Email: solanum.tuberosum89@gmail.com
}

\begin{tabular}{|c|c|}
\hline ARTICLE INFO & ABSTRACT \\
\hline $\begin{array}{l}\text { Article History } \\
\text { Received October 23, } 2019 \\
\text { Revised December 24, } 2019\end{array}$ & $\begin{array}{l}\text { Pear peel offers potential health benefits, but no study has revealed the } \\
\text { antioxidant and extracts from the pear peel. In this study, the total capacity of } \\
\text { the phenolic extract of pears and the influence of pear peel extracts belong to }\end{array}$ \\
\hline $\begin{array}{l}\text { Accepted January 6, } 2020 \\
\text { Keywords }\end{array}$ & $\begin{array}{l}\text { Packham's Pears and Yali's Pears on antioxidant activity have been } \\
\text { determined. Using the Folin-Ciocalteu method and aluminum chloride }\end{array}$ \\
\hline Phytochemicals & colorimetric method, the total phenolic contents and total flavonoid contents \\
\hline Phenolics & were determined, respectively. The extracts obtained, the maceration \\
\hline Flavonoids & method utilized using ethanol $70 \%$ as a solvent. The total phenolic content of \\
\hline Pear peels & Packham's pear peel and Yali's pear peel extracts were $62.04 \pm 1,044 \mathrm{mg} G A E /$ \\
\hline Antioxidant & $\begin{array}{l}\mathrm{g} \text { and } 57.50 \pm 0.817 \mathrm{mg} \mathrm{GAE} / \mathrm{g} \text { respectively, while flavonoid contents in } \\
\text { Packham's pear peel and Yali's pear peel are } 7.40 \% \text { for Packham's pears and }\end{array}$ \\
\hline Doi & $6.03 \%$ for Yali's pears. This research reveals that Packham's pear peel has \\
\hline 10.22219/farmasains.v4i2.10166 & $\begin{array}{l}\text { more phenolic and flavonoid contents than Yali's pear peel. Pear peel has the } \\
\text { potential to be extracted and processed into a consumable supplement or } \\
\text { even drug. }\end{array}$ \\
\hline
\end{tabular}

\section{INTRODUCTION}

Free radicals cause diseases in the body. Free radicals are atoms or clusters that have one or more electrons. Free radicals can also found in the surrounding environment, some metals (such as iron and copper), cigarette smoke, drugs, packaged foods, addictive substances, etc (Dröge, 2002). In protecting the body from free radical attacks, the antioxidant compounds work to stabilize free radicals by overpowering the lack of electron of free radicals and thus blocking chain reactions. Antioxidants are a necessary substance to neutralize free radicals and prevent damage done by free radicals by supplementing the lack of free radicals and suppressing the chain reaction of free radical forms 
Other efforts to suppress oxidative stress in the body are balancing the antioxidant and prooxidant levels in the body by consuming foods as a source of bioactive substances to increase antioxidant capacity and plasma. Foods containing bioactive compounds are fruits and vegetables. Fruits and vegetables are a source of vitamins, minerals, and bioactive compounds that are helpful in the prevention of disease. Fruit and vegetable consumption does not generally include the skin or peel. Therefore, the peel is often classified as non-eaten and discarded as waste. Nevertheless, some studies indicate that the peel of fruits and vegetables has the potential for bioactive compounds, even a higher quantity than pulp. Fruits peel and vegetables can be developed as a source of bioactive substances that can prevent degenerative diseases from happening. Some studies indicate that bioactive compounds derived from fruits peel or vegetables can prevent diabetes mellitus, atherosclerosis, cancer, cardiovascular disease, or antioxidants. (Wolfe, Wu \& Liu, 2003; Khlifi et al., 2005; Nurliyana, Syed Zahir, Mustapha Suleiman, Aisyah \& Kamarul Rahim, 2010; Nugraheni, Santoso \& Wuryastutiet, 2011).

Pear (Pyrus spp.) is one of the first broadly consumed fruits within the world. The natural product is usually eaten fresh and in processed nourishments such as juice, puree, and jams. Moreover, pears utilized as a traditional cure in China and Korea due to their antitussive, antiinflammatory, and diuretic exercises (Jung, Lee, Jeong \& Choiet, 2004; Cui, Nakamura, Ma, Li \& Kayahara, 2005). Pears contain a wide range of phenolic compounds comprising distinctive flavonoid classes [anthocyanins, flavonols, monomeric ('catechins'), and polymeric flavan 3-ols (proanthocyanidins, condensed tannins), and flavanones], hydroxyphenyl acids (generally hydroxycinnamic acids inferred from caffeic acid and p-coumaric acid) and the p-hydroquinone-glucoside arbutin (Fischer et al., 2007). There is a benefit to the pear peel, but no study has revealed about the antioxidant and extracts from the pear peel. The study aims to determine the total capacity of the phenolic extract of pears and the influence of pear peel extracts on antioxidant activity.

\section{RESEARCH METHOD}

\section{Materials and Tools}

\section{Plant Material}

Packham's Pears and Yali's Pears. The sample used in this research was pear skin obtained from the Caring
Market, Bandung, West Java.

\section{Chemical Material}

Other materials used were ethanol 70\%, ascorbic acid, gallic acid, Folin-Ciocalteu's phenol reagent purchased from Sigma Chemical Co. (Singapore), aqua dest, chloroform, toluene, acetone, $25 \%$ ammonia, $2 \mathrm{~N}$ and $10 \%$ hydrochloric acid, dragendorff reagent, Mayer reagent, Mg powder, amyl alcohol, sodium hydroxide, gelatin, Fe (III) chloride $1 \%$, anhydrous acetic acid.

\section{Tools}

The tools used are sifters, cups, oven, desiccator, maceration bottles, Erlenmeyer flasks, rotary evaporator, analytical scales, micropipette, and spectrophotometric measurements were performed on Shimadzu ultraviolet (UV)-1600 spectrometer (Shimadzu, Kyoto, Japan).

\section{Method}

\section{Sample Preparation}

The sample dried for three days and then ground using a blender and filtered until it reached powdery consistency.

\section{Extractions}

50-gram sample was extracted by maceration in $200 \mathrm{~mL}$ of ethanol $70 \%$ at room temperature for 24 hours with many stirring. The residues and the extract separated by filter paper. The residues obtained were re-extracted twice with the fresh portion of the extraction solvent. The extract recovered from three extractions combined with an excess of the solvent distilled-off in a vacuum rotary evaporator at $50^{\circ} \mathrm{C}$. The obtained semisolid extracts were quantitatively transferred to the extraction solvent and preserved at $10^{\circ} \mathrm{C}$ until used for further experiments.

\section{Qualitative Phytochemical Screening}

Phytochemical compounds carried out for all extracts with the following methods (Sermakkani \& Thangapandian, 2010):

Alkaloid: 0.1 gram extract added $10 \mathrm{ml}$ chloroform and a few drops of ammonia. The chloroform fractions are separated and sharpened with a few drops of $\mathrm{H} 2 \mathrm{SO} 4$. Acid fractions are extracted and divided into three tubes, and then reduced using Dragendorf, Meyer, and Wagner. The existence of the alkaloid characterized by the formation of white deposits in Meyer's reenactment, the red deposit of Dragendorf reduction, and the brown deposit of 
Wagner's repository.

Steroid/triterpenoid: A total of $1 \mathrm{~g}$ samples dissolved with $25 \mathrm{ml}$ of hot ethanol, then filtered into a porcelain platter and dehydrated. The residue is dissolved with ether, transferred into a reaction tube, added three drops of anhydrated acetic acid, and drops $\mathrm{H} 2 \mathrm{SO} 4$ (Lieberman Burchard test). Red or purple indicates a triterpenoid, and green or blue indicates a steroid.

Flavonoid: A sample added to magnesium $0.1 \mathrm{mg}$ and $0.4 \mathrm{ml}$ of amyl alcohol (a mixture of chloric acid $37 \%$ and ethanol $96 \%$ of the same volume) and $4 \mathrm{ml}$ of alcohol. When the mixture's color is red, yellow, or orange on the lining of amyl alcohol, there was indicates flavonoid.

Tanin: 1 gram extract added ten drops fecl3 10\% When a color changes to dark blue, the sample contains tannin.

\section{Determination of Total Phenolic contents}

$0.5 \mathrm{~g}$ extract mixed with $0.1 \mathrm{ml}$ of Folin-Ciocalteu Reagents, incubated at room temperature for 15 minutes. Sodium carbonate $2.5 \mathrm{ml}$ was added and incubated for 30 minutes. The mixture added $400 \mu \mathrm{L}$ of distilled water, and the volume adjusted to $1 \mathrm{~mL}$. The mixture was vortexed and incubated at $45^{\circ} \mathrm{C}$ for $30 \mathrm{~min}$ before cooling rapidly with ice, then determined by UV-Vis spectrophotometry at I 760 $\mathrm{nm}$. The high acid with a concentration of 25-300 $\mathrm{mg} / \mathrm{ml}$ was made as a calibration curve and analyzed with triple repetition (Diaz, Jeong, Lee, Khoo \& Koyyalamudiet, 2012).

\section{Determination of Total Flavonoid contents}

Total flavonoid content determined by the aluminum chloride method. Remarkably $0.5 \mathrm{~mL}$ sample and $300 \mu \mathrm{l}$ NaNO2 shaken for 10 seconds and left at room temperature for 10 seconds. After standing, added $300 \mu \mathrm{L}$ of AlCl3 (1:10 w/v) and $2 \mathrm{~mL}$ of $\mathrm{NaOH}$ $(1 \mathrm{M})$. Furthermore, the aquadest was added to a mixture of reactions and then shook for 10 seconds and measured at $510 \mathrm{~nm}$ wavelength. Quercetin was used as a standard calibration curve with a concentration range by $0-1200 \mu \mathrm{g} / \mathrm{mL}$, and the sample was analyzed triple repetition (Diaz et al., 2012).

\section{Data Analysis}

The real difference for total phenol and total flavonoid analyzed using one-way ANOVA SPSS version 22 .

\section{RESULT AND DISCUSSIONS}

\section{Pear Peels Extraction Result}

The maceration method is the extraction method used in this experiment because the maceration is the simplest method for the desired active compound synthesizing. Moreover, it can be done efficiently only by soaking simplistic in a solvent that is helped by stirring at room temperature (Sari \& Triyasmoro, 2017). The solvent used is ethanol $70 \%$ because it attracts the active substances found in the sample to be semipolar. Maceration took three days and was obtained a solution of dark brown and then filtered. The results from 50 grams of fresh pear obtained rendement extract of $18.54 \%$ for Packham's pear and $22.08 \%$ from Yali's pear. The effectiveness of the extraction process is affected by several factors. Firstly, the type of solvent used determines the extracted compound, the number of solvents extracted, and the extraction process's speed. Secondly, the method used because the selection of the correct method can produce a good extract. Moreover, thirdly, the size of the particle, the smaller the particle size, the larger the area of contact between solids and solvent, and the shorter of diffuse, which makes mass transfer rates higher.

\section{Qualitative Phytochemical Screening}

The Phytochemical screening includes tests of alkaloids, flavonoids, saponins, tannins, steroids, and triterpenoids. The result of phytochemical screening of pear peel extracts is a positive reaction for flavonoids, tannins, saponins, and alkaloids, while adverse reactions for steroids and terpenoids (Table 1).

Determination of total phenolic levels used the Folin Ciocalteu method. This method is the most commonly used method to determine the total

Table 1. Qualitative phytochemical screening results in Packham's Pear Peel and Yali's Pear Peel.

\begin{tabular}{lllll}
\hline Samples & Flavonoids & Tannins & Saponin & $\begin{array}{c}\text { Alkaloids } \\
\text { Terpenoids }\end{array}$ \\
\hline Packham's pear peel & ++ & + & + & + \\
Yali's pear peel & + & + & + & + \\
\hline
\end{tabular}

$(++)$, highly present; (+), present; (-), absent.

The table shows the flavonoid contained in Packham's pear peel is more potent than Yali's pear. It is probably relevant to its antioxidant activity. It means that the extract of flavonoid also contains phenolic compounds because flavonoid is one of the most significant parts of the phenolic compounds. 
Table 2. Total flavonoid contents of Packham's and Yali's pear peels.

\begin{tabular}{|c|c|c|c|c|c|}
\hline Samples & Absorbances & $\begin{array}{l}\text { Concentration } \\
(\mathrm{mg} / \mathrm{ml})\end{array}$ & $\begin{array}{l}\text { Total Flavonoid } \\
\text { Contents (\%) }\end{array}$ & $\begin{array}{l}\text { Average Total } \\
\text { Flavonoid } \\
\text { Contents (\%) }\end{array}$ & $\pm S D$ \\
\hline \multirow[t]{3}{*}{ Packham's Pear Peel } & 0.653 & 0.073 & 7.33 & 7.40 & 0.235 \\
\hline & 0.659 & 0.077 & 7.66 & & \\
\hline & 0.660 & 0.072 & 7.21 & & \\
\hline \multirow[t]{2}{*}{ Yali's Pear peel } & 0.517 & 0.059 & 5.88 & 6.03 & 0.177 \\
\hline & 0.516 & 0.061 & 6.12 & & \\
\hline
\end{tabular}

Table 3. Total flavonoid contents of Packham's and Yali's pear peels.

\begin{tabular}{llllll}
\hline Samples & Absorbances & $\begin{array}{l}\text { Concentration } \\
(\mathrm{mg} / \mathrm{ml})\end{array}$ & $\begin{array}{l}\text { Total Flavonoid } \\
\text { Contents (\%) }\end{array}$ & $\begin{array}{l}\text { Average Total } \\
\text { Flavonoid } \\
\text { Contents (\%) }\end{array}$ & \pm SD \\
\hline Packham's Pear Peel & 0.653 & 0.073 & 7.33 & 7.40 & 0.235 \\
& 0.659 & 0.077 & 7.66 & & \\
\hline Yali's Pear peel & 0.660 & 0.072 & 7.21 & 6.03 & 0.177 \\
& 0.517 & 0.059 & 5.88 & & \\
& 0.522 & 0.061 & 6.09 & & \\
& 0.516 & 0.061 & 6.12 & & \\
\hline
\end{tabular}

phenolic content in plants because it has a more straightforward process. Folin Ciocalteau reagent used because phenolic compounds can react with Folin to form a solution that can measure absorption. Analysis of total phenolic content done using the Folin-Ciocalteu method, whose absorbance measured at a wavelength of $765 \mathrm{~nm}$ (Pourmorad, Hosseinimehr \& Shahabimajd, 2006). The standard solution used is gallic acid, which is a natural phenolic and a stable one. Gallic acid included in the phenolic compounds derived from hydroxybenzoic acid, which classified as pure phenolic acid. Gallic acid is reacted with the Folin Ciocalteau reagent to produce a yellow color, which indicates that it contains phenolic. After that, it is added with a solution of $\mathrm{Na} 2 \mathrm{CO} 3$ to provide a base environment. During the reaction, the hydroxyl group in the phenolic compound reacts with the Folin Ciocalteau reagent, forming a blue molybdenum-tungsten complex with an unknown structure detected with a spectrophotometer.

The linear regression equation obtained is $\mathrm{y}=$ $0.0061 x+0.0144$ with a correlation coefficient $(r)$ of 0.9945 . The determination of phenol levels from $70 \%$ ethanol extract of pear skin was carried out through $3 x$ replication and shown in Table 2 . Based on the results of the table above, the total phenolic content of Packham's pear extract and Yali's pear skin were $62.04 \pm 1,044 \mathrm{mg} \mathrm{GAE} / \mathrm{g}$ and $57.50 \pm 0.817$ $\mathrm{mg}$ GAE/g respectively, which means that in each gram of pear skin ethanol extract there is a phenolic compound equivalent to $62.04 \mathrm{mg}$ gallic acid for
Packham's pears and $57.50 \mathrm{mg}$ gallic acids for Yali's pears.

Phenolic compounds contained in pear skin extracts are the result of potential secondary metabolites as a source of raw material for drugs that act as antioxidants, and the higher the mass (indicated by grams), the greater the content of phenolic compounds which have the potential as antioxidants.

\section{Total Flavonoid Contents}

Determination of total flavonoid levels was done by using the colorimetric method. This method uses the $\mathrm{FeCl} 3$ reagent to form a reaction between $\mathrm{AlCl} 3$ and the flavonoid group to form a complex between a hydroxyl group and a neighboring ketone or with a neighboring hydroxyl group. $\mathrm{AlCl} 3$ will react with ketone groups on $\mathrm{C} 4$ and $\mathrm{OH}$ groups on $\mathrm{C} 3$ or $\mathrm{C} 5$ on flavone or flavonol compounds to form a yellowish stable compound. The compound used as a standard in determining the level of flavonoids is quercetin because quercetin is a flavonoid group of flavonols which has keto groups on C-4 atoms and also hydroxyl groups on neighboring $\mathrm{C}-3$ and $\mathrm{C}-5$ atoms (Sari \& Triyasmoro, 2017).

The linear regression equation can be obtained from the calibration curve $t$, namely $y=0.0029 x+0.064$ with a correlation coefficient $(r)=0.9927$. From the table above, the result of total flavonoid levels in Packham's pear peel is also higher than Yali's pears, which is $7.40 \%$ for Packham's pear peel and $6.03 \%$ for Yali's pear peel. These results are relevant to the 
results shown in phytochemical screening, in terms, flavonoids in Packham's pear peel are stronger in color than Yali's pear peel. Flavonoid compounds have many benefits in health, including antioxidants, antidermatitis, chemopreventive, anticancer, and antiviral (Kamboh et al., 2015). Therefore, the ethanol extract of pear peel can be used as an additional therapy for preventing disease by being made into a consumable drug.

\section{CONCLUSION}

Based on the results of the performed research, it can be concluded that the extract of pear peels in $70 \%$ ethanol contains flavonoid compounds, tannins, alkaloids, and saponins. The content of total phenol compounds and total flavonoids in Packham's pear peel is higher than in Yali's pear peel. However, both samples have compounds that have potential as antioxidants.

\section{REFERENCES}

Cui, T., Nakamura, K., Ma, L., Li, J. Z., \& Kayahara, H. (2005). Analyses of arbutin and chlorogenic acid, the major phenolic constituents in oriental pear. Journal of Agricultural and Food Chemistry, 53(10), 3882-3887.

Sari, D. I., \& Triyasmono, L. (2017). Rendemen dan Flavonoid Total Ekstrak Etanol Kulit Batang Bangkal (Nauclea subdita) dengan Metode Maserasi Ultrasonikasi. Jurnal Pharmascience, 4(1), 48-53.

Diaz, P., Jeong, S. C., Lee, S., Khoo, C., \& Koyyalamudi, S. R. (2012). Antioxidant and anti -inflammatory activities of selected medicinal plants and fungi containing phenolic and flavonoid compounds. Chinese Medicine, 7(1), 26.

Droge, W. (2002). Free radicals in the physiological control of cell function. Physiological reviews, 82(1), 47-95.

Fischer, T. C., Gosch, C., Pfeiffer, J., Halbwirth, H., Halle, C., Stich, K., \& Forkmann, G. (2007). Flavonoid genes of pear (Pyrus communis). Trees, 21(5), 521-529.

Jung, U. J., Lee, M. K., Jeong, K. S., \& Choi, M. S. (2004). The hypoglycemic effects of hesperidin and naringin are partly mediated by hepatic glucose-regulating enzymes in $\mathrm{C} 57 \mathrm{BL} / \mathrm{KsJ}-\mathrm{db} /$ $\mathrm{db}$ mice. The Journal of nutrition, 134(10), 2499-2503.
Kamboh, A. A., Arain, M. A., Mughal, M. J., Zaman, A., Arain, Z. M., \& Soomro, A. H. (2015). Flavonoids: health promoting phytochemicals for animal production-a review. Journal of Animal Health and Production, 3(1), 6-13.

Khlifi, S., El Hachimi, Y., Khalil, A., Es-Safi, N., \& El Abbouyi, A. (2005). In vitro antioxidant effect of Globularia alypum L. hydromethanolic extract. Indian Journal of Pharmacology, 37(4), 227-231.

Nugraheni, M., Santoso, U., \& Wuryastuti, H. (2011). Potential of Coleus tuberosus as an antioxidant and cancer chemoprevention agent. International Food Research Journal, 18(4), 1471-1480.

Nurliyana, R. D., Syed Zahir, I., Mustapha Suleiman, K., Aisyah, M. R., \& Kamarul Rahim, K. (2010). Antioxidant study of pulps and peels of dragon fruits: a comparative study. International Food Research Journal, 17(2), 367-375.

Pourmorad, F., Hosseinimehr, S. J., \& Shahabimajd, N. (2006). Antioxidant activity, phenol and flavonoid contents of some selected Iranian medicinal plants. African journal of biotechnology, 5(11), 1142-1145.

Sermakkani, M., \& Thangapandian, V. (2010). Phytochemical screening for active compounds in Pedalium murex L. Recent Research in Science and Technology, 2(1), 110114.

Wolfe, K., Wu, X., \& Liu, R. H. (2003). Antioxidant activity of apple peels. Journal of Agricultural and Food Chemistry, 51(3), 609-614. 